Pesq. Vet. Bras. 29(4):345-352, abril 2009

\title{
Variação da força de resistência à micro-tração de fragmentos de ossos corticais preservados em diversos meios e a fresco: estudo experimental em coelhos ${ }^{1}$
}

\author{
Renato L. Sampaio ${ }^{2 \star}$, Moacir S. Lacerda ${ }^{2}$, Pedro Carlos L. Oliveira ${ }^{2}$, João \\ Cláudio do Carmo Paneto ${ }^{2}$, Eustáquio R. Bittar², Gillberto A. Borges ${ }^{3}$, Graciela \\ Mendes M. Camacho ${ }^{4}$ e Eduardo M. Braga ${ }^{5}$
}

\begin{abstract}
Sampaio R.S., Lacerda M.S., Oliveira P.C.L., Paneto J.C.C., Bittar E.R., Borges G.A., Camacho G.M.M. \& Braga E.M. 2009. [Variation of the resistance force to the microtraction of fragments of cortical bones preserved in several means and fresh: Experimental study in rabbits.] Variação da força de resistência à micro-tração de fragmentos de ossos corticais preservados em diversos meios e a fresco: estudo experimental em coelhos. Pesquisa Veterinária Brasileira 29(4):345-352. Instituto de Estudos Avançados em Veterinária “José Caetano Borges", Universidade de Uberaba, Av. Afrânio Azevedo 2140, Bairro Olinda, Uberaba, MG 38020-450, Brazil. E-mail: relisampa@terra.com.br

Due to the increasing use of cortical bone allografts in orthopedic surgeries, de knowledge of its biomechanics characteristics during preservation time is needed. The present study consisted in the analyses of the resistance power to the micro-traction of samples of rabbit cortical bones preserved in several means for up to 180 days and fresh. The results showed that the resistance and the preservation time presented an inversely proportional relation, meaning that, the longer the time of preservation, the shorter the physical resistance evaluated in the biomechanical rehearsal of resistance to the micro-traction. The glycerin has presented lower values in relation to the resistance test, showing, after 30 days, only $24.58 \%$ of the present power in the fresh bone, and by 180 days, $1.76 \%$. The samples submitted to autoclavation also showed low values by the end of the experiment, while they remained with just $12.31 \%$ of the power present in the fresh bone. The bones preserved in homologous plasma, Dakin liquid and the ones cryopreserved showed the best levels of resistance at the end of the experiment, remaining, respectively with $82.47,70.34$ and $66.72 \%$ of the maximum power, while compared with the resistance of the fresh bones. The conclusion is that the choice of methodology and time of preservation interfered directly in the biomechanics of the cortical bones, promoting decrease of the resistance capacity to the traction along the period of preservation.
\end{abstract}

INDEX TERMS: Bone graft, bone preservation, bone resistance, bone micro-traction, rabbits.

\footnotetext{
${ }^{1}$ Recebido em 31 de outubro de 2007.

Aceito para publicação em 11 de março de 2009.

${ }^{2}$ Curso de Medicina Veterinária, Instituto de Estudos Avançados em Veterinária "José Caetano Borges", Universidade de Uberaba (Uniube), Av. Afrânio Azevedo 2140, Bairro Olinda, Uberaba, MG 38.020-450, Brasil. *Autor para correspondência: Relisampa@terra.com.br

${ }^{3}$ Curso de Odontologia, Laboratório de Resistência de Materiais, vinculado ao Núcleo Integrado de Pesquisa em Odontologia, Uniube, Av. Nenê Sabino 1801, Bairro Universitário, Uberaba, MG 38.055-500.

${ }^{4}$ Aluna de Iniciação Científica, Hospital Veterinário de Uberaba, Uniube, Av. do Tutuna 720, Tutunas, Uberaba, MG 38.061-500.

${ }^{5}$ Residente da área de Cirurgia de Pequenos Animais do Hospital Veterinário de Uberaba, vinculado ao Curso de Medicina Veterinária, Hospital Veterinário de Uberaba, Uniube, Uberaba, MG.
}

RESUMO.- Devido ao crescente uso dos aloenxertos nas cirurgias ortopédicas, há a necessidade do conhecimento de suas características biomecânicas ao longo do tempo de preservação. O presente trabalho consistiu na análise da força de resistência à micro-tração de amostras de ossos corticais de coelho preservadas em diversos meios por até 180 dias e a fresco. Os resultados revelaram que a resistência e o tempo de preservação apresentaram uma relação inversamente proporcional, significando que, quanto maior o tempo de preservação, menor a resistência física avaliada no ensaio biomecânico de resistência à micro-tração. Dos meios utilizados, a glicerina 
apresentou menores valores quanto ao teste de resistência, demonstrando, após 30 dias de preservação, apenas $24,58 \%$ da força presente no osso a fresco e, aos 180 dias, $1,76 \%$. As amostras submetidas à autoclavagem também demonstraram baixos valores ao final do experimento, quando permaneceram com apenas $12,31 \%$ da força presente no osso a fresco. Os ossos preservados em plasma homólogo, líquido de dakin e aqueles criopreservados apresentaram os melhores índices de resistência ao final do experimento, permanecendo, respectivamente, com 82,47; 70,34 e 66,72\% da força máxima quando comparados com a resistência dos ossos frescos. Concluiu-se que a escolha do método e o tempo de preservação interferiu diretamente na biomecânica dos ossos corticais, promovendo a diminuição da capacidade de resistência à tração ao longo do período de preservação.

TERMOS DE INDEXAÇÃO: enxerto ósseo, preservação óssea, resistência óssea, micro-tração óssea, coelhos.

\section{INTRODUÇÃO}

O tecido ósseo é alvo de inúmeras doenças que comprometem a locomoção dos animais e do homem. Algumas podem causar, além dos efeitos locais no osso, sinais sistêmicos, a exemplo de algumas moléstias metabólicas e dos tumores ósseos, os quais podem originar metástases (Fitch et al. 1997, Vieira 1998, Saraiva \& LazarettiCastro 2002).

Dos métodos utilizados no tratamento das afecções ortopédicas, os enxertos destacam-se como um dos mais importantes, sendo amplamente empregados quando se necessita promover a reparação em áreas com grande perda óssea, como ocorre na osteotomia para o tratamento de cistos ou neoplasias e no tratamento das fraturas cominutivas (Feofiloff \& Jesus-Garcia 1996, Cunha et al. 1998, Lourenço \& Franco 1998, Silva et al. 2000b, Miranda et al. 2005).

A técnica de transplante do tecido ósseo já é empregada há décadas, existindo grande variação na forma de preservação e no tempo de estocagem para cada meio. Costa (1996) testou a utilização de osso cortical conservado em glicerina na reparação de falhas ósseas em cães, relatando que o meio testado preservou as características osteoindutora e osteocondutora dos enxertos; porém, verificou que os mesmos tornaram-se menos resistentes.

Cavassani et al. (2001), também testaram a glicerina como meio de preservação de fragmentos ósseos de ratos. Ao final do experimento, os autores verificaram que os implantes realizados no tecido subcutâneo e intramuscular apresentaram resposta osteogênica positiva, concluindo que a glicerina foi um bom meio para a conservação de fragmentos ósseos para uso em enxertos, uma vez que a função osteoindutora foi preservada.

Contudo, Del Carlo et al. (1999), ao testarem vários métodos de conservação de aloenxertos ósseos, concluíram que a glicerina não foi eficiente na manutenção da esterilização das amostras, o que contribuiu para alterar as características biomecânicas das mesmas. No mesmo experimento, os autores observaram que os aloenxertos conservados sob refrigeração a $4^{\circ} \mathrm{C}$ e aqueles mantidos em solução de timerosal também não mantiveram as amostras livres de contaminantes, justificando a falha na aplicação dos mesmos. Já as amostras congeladas em solução fisiológica com antibiótico, tiveram preservadas a esterilidade e a biomecânica, tendo sido eficazes no transplante.

A liofilização e o congelamento também têm sido sugeridos como métodos de estocagem de ossos corticais para a execução de enxertos heterólogos. Em estudos comparativos, Macedo et al. (1999) e Duarte \& Schaeffer (2000), compararam a resistência à compressão de ossos bovinos congelados e liofilizados. Os resultados de ambos os experimentos mostraram que, ao final dos ensaios, não houve diferença estatística significativa, na comparação da resistência à compressão, entre os grupos de estudo.

Resultados semelhantes foram obtidos por Galia et al. (2005), os quais não observaram diferenças na resposta inflamatória e na capacidade de osteointegração entre enxertos congelados e liofilizados aplicados em ratos. Porém, outros estudos demonstraram que, apesar do congelamento seguido de liofilização reduzir consideravelmente a intensidade da resposta imunológica do hospedeiro, este método promove alterações indesejáveis das características biomecânicas, com redução da resistência óssea (Boyce et al. 1999, Matter et al. 2001).

Volpon \& Costa (2000), ao testarem, comparativamente, amostras de osso corticoesponjoso, quimicamente preparado e esterilizado em óxido de etileno, para a preservação em temperatura ambiente, com amostras do mesmo osso no seu estado natural, observaram que os ossos tratados apresentaram maior resistência ao teste de compressão, concluindo que este tipo de enxerto tem resistência mecânica adequada e é uma alternativa para a substituição do enxerto autógeno fresco; sendo viável para a constituição de banco de ossos.

Já, Silva et al. (2000a), ao avaliarem as alterações histológicas em enxertos de osso homógeno, preparados e armazenados com duas técnicas diferentes, verificaram que, 30 dias após o implante, os ossos não descalcificados e armazenados a $-70^{\circ} \mathrm{C}$ ainda apresentavam consistência de osso cortical, com absorção da superfície do endósteo, diminuição da camada cortical e aumento da cavidade medular. Porém, as amostras que foram descalcificadas, liofilizadas e armazenadas em temperatura ambiente apresentaram, após 30 dias da realização do implante, consistência amolecida; sendo que, ao exame microscópico, os ossos estavam preenchidos por material acelular e avascular, assemelhando-se à cartilagem. Com isto, concluíram que existem diferenças histológicas nas amostras descalcificadas e liofilizadas, quando comparadas com aquelas congeladas a $-70^{\circ} \mathrm{C}$.

O efeito da desmineralização sobre o potencial osteo- 
indutor da matriz óssea homóloga também foi testada por Del Carlo et al. (2003b), utilizando ossos corticais de coeIho como modelo experimental. Os resultados permitiram concluir que o ácido clorídrico, 0,6 N, promoveu desmineralização eficaz e manteve o potencial osteoindutor das amostras investigadas e que, devido a fatores indutores inerentes, que atuam sobre as células dos tecidos adjacentes, houve promoção de quimiotaxia, mitose e diferenciação celular no local do implante. Resultados semeIhantes foram obtidos por Silva et al. (2003), os quais observaram que a matriz óssea homóloga desmineralizada acelera o processo de formação óssea, servindo de arcabouço para a penetração celular a partir dos tecidos adjacentes do hospedeiro, determinando a osteocondução no local de aplicação do enxerto. Com isto, concluíram que a matriz desmineralizada pode ser considerada material alternativo a outros tratamentos no preenchimento de falhas osteoperiosteais.

O mel também tem sido utilizado como meio de preservação tecidual e Amendola et al. (2003) verificaram, em estudo realizado com segmentos ósseos de cães mantidos neste meio, que de 12 animais submetidos ao transplante, 8 apresentaram incorporação do implante sem complicações; ao passo que, nos 4 restantes, houve reabsorção do material implantado.

Mais recentemente, Giovani et al. (2006), compararam os efeitos da criopreservação de ossos a $-80^{\circ} \mathrm{C}$ com a preservação em glicerol a $98 \%$ em temperatura ambiente. As análises microbiológicas dos meios testados, decorridos um ano, não demonstraram crescimento fúngico ou bacteriano, permitindo concluir que os métodos estudados apresentaram similaridade nos resultados, estando ambos indicados na preservação de ossos trabeculares para enxerto.

O xenoenxerto utilizando osso fetal bovino acelular e desmineralizado aplicado no subcutâneo de ratos também foi testado como alternativa ao alotransplante por Zambuzzi et al. (2006). Considerando-se que o material não induziu destruição tecidual ou recrutamento do sistema imunológico e que o mesmo foi parcialmente absorvido e bem tolerado pelo tecido do receptor, os autores concluíram que o material testado foi biocompatível.

O tratamento das falhas ósseas também tem sido realizado com eficiência através da utilização do auto-enxerto de medula óssea (Barros et al. 2001a,b); bem como mediante a aplicação de materiais sintéticos e biológicos como substitutos ósseos, representados pela hidroxiapatita pura, ou associada ao colágeno, e o polímero de mamona (Franco et al. 2001, Keating \& Mcqueen 2001, Del Carlo et al. 2003a, Sun et al. 2003, Giordano et al. 2006).

A indicação para a aplicação do enxerto ósseo cortical deve levar em consideração a origem do osso para enxerto, o método de preservação e a técnica de aplicação dos mesmos. Tornam-se também necessário conhecer as variações das características biomecânicas resultantes do processo de preservação de enxertos ósseos nos meios disponíveis, aspectos estes que norteiam este estudo.

\section{MATERIAL E MÉTODOS}

Animais. Para a realização desta proposta de trabalho foram utilizados 42 coelhos da raça Nova Zelândia, clinicamente sadios, com idade de 75 dias e pesando, em média, $2,5 \mathrm{~kg}$.

Colheita e preservação das amostras de ossos corticais. Após a eutanásia, praticada com a aplicação intraperitoneal de $25 \mathrm{mg} / \mathrm{kg}$ de Tiopental sódico a 2,5\%, promovendo-se anestesia geral, seguida da aplicação de cloreto de potássio a 10\%, pela mesma via, até se constatar parada cárdio-respiratória, procedeu-se à colheita das costelas, referentes àquelas localizadas do $4^{\circ}$ ao $11^{\circ}$ par. Após a colheita, realizou-se a remoção dos tecidos moles adjacentes aos ossos, mediante a raspagem com lâmina de bisturi. Já limpas, as amostras foram lavadas com solução fisiológica estéril e acondicionadas em tubos tipo Falcon, de $50 \mathrm{ml}$, de acordo com a distribuição dos grupos.

Divisão dos grupos. Foram colhidas, ao todo, 672 amostras de costelas, as quais foram separadas em 8 grupos com 84 costelas cada, contendo, cada grupo, costelas referentes ao mesmo par (Quadro 1). Os grupos (G) foram numerados de 1 a 8 , de acordo com o meio de preservação a ser testado, como apresentado no quadro 1. Cada um dos 8 grupos, formados por 84 amostras da mesma costela, foi novamente dividido em 7 subgrupos (T) com 12 amostras cada, correspondendo, cada subgrupo, a um período de tempo de preservação, a saber: T0 $=$ fresco; $\mathrm{T} 1=30$ dias; $\mathrm{T} 2=60$ dias; $\mathrm{T} 3=90$ dias; $\mathrm{T} 4=120$ dias; T5 $=150$ dias; T6 $=180$ dias (Quadro 1).

Procedimento de avaliação da resistência. Ao final do intervalo de tempo determinado para cada subgrupo de amostras mantidas preservadas, os ossos foram submetidos ao teste de análise de resistência à micro-tração, utilizando-se equipamento Emic DL $3000^{6}$, com célula de força Trd 21 com capacidade de $50 \mathrm{~N}$ (5kgf) e resolução de leitura de $0,01 \mathrm{~N}$ (1 kgf). As amostras referentes ao subgrupo T0 de todos os grupos foram submetidas ao teste de resistência à micro-tração logo após a colheita, para a mensuração da resistência dos ossos corticais em seu estado natural. As amostras criopreservadas e aquelas congeladas no plasma homólogo foram mantidas em ambiente climatizado, a $20^{\circ} \mathrm{C}$, até atingirem o descongelamento; enquanto que as amostras mantidas refrigeradas permaneceram no mesmo ambiente climatizado por um período de 2 horas antes da realização dos testes. Para a realização do teste biomecânico de resistência à micro-tração, as costelas foram preparadas promovendo-se a osteotomia das extremidades, de forma que cada amostra apresentasse $2,5 \mathrm{~cm}$ de comprimento. Após esta padronização, as amostras foram fixadas em garras autotravantes por efeito de alavanca, fixadas à máquina universal de ensaios e submetidas à aplicação de força progressiva de micro-tração, a qual consiste em submeter 0 material a um esforço que tende a alongá-lo até a ruptura, sendo que as cargas são mensuradas pela própria máquina, permitindo conhecer como as amostras reagem aos esforços de tração e quais os limites de tração que suportam. A máquina de

\footnotetext{
${ }^{6}$ Máquina universal de ensaios, eletromecânica e microprocessada (www.emic.com.br). Ensaios realizados no Laboratório de Resistência de Materiais, vinculado ao Núcleo Integrado de Pesquisa em Odontologia, da Universidade de Uberaba.
} 
teste utilizada encontra-se interligada ao computador que possui um software (Tesc $1.10^{7}$ ). As deformações sofridas pelas amostras são registradas pela célula de força, a qual envia estes resultados para o computador que, com o auxílio do software, calcula automaticamente os valores finais das seguintes variá-

\footnotetext{
${ }^{7}$ Programa de automação de ensaios, compatível com as máquinas de ensaios microprocessadas EMIC.

Quadro 1. Divisão e identificação dos grupos formados por amostras de costelas e que foram submetidos, ao final de cada período, ao teste de resistência a microtração
}

\begin{tabular}{|c|c|c|c|c|}
\hline $\begin{array}{l}\text { Identifica- } \\
\text { ção no } \\
\text { tubo }\end{array}$ & $\begin{array}{l}\text { № de } \\
\text { amos- } \\
\text { tras }\end{array}$ & $\begin{array}{l}\text { Identificação } \\
\text { anatômica } \\
\text { da amostra }\end{array}$ & Meio de preservação & $\begin{array}{l}\text { Tempo de } \\
\text { preservação } \\
\text { (dias) }\end{array}$ \\
\hline $\begin{array}{l}\text { T1G1 } \\
\text { T2G1 } \\
\text { T3G1 } \\
\text { T4G1 } \\
\text { T5G1 } \\
\text { T6G1 }\end{array}$ & $\begin{array}{l}12 \\
12 \\
12 \\
12 \\
12 \\
12\end{array}$ & $4^{\underline{a}}$ costela & $\begin{array}{l}\text { Solução aquosa } \\
\text { de iodo povidine } \\
\text { a } 10 \% \text {, refrigera- } \\
\text { do a } 4^{\circ} \mathrm{C}\end{array}$ & $\begin{array}{c}30 \\
60 \\
90 \\
120 \\
150 \\
180\end{array}$ \\
\hline $\begin{array}{l}\text { T1G2 } \\
\text { T2G2 } \\
\text { T3G2 } \\
\text { T4G2 } \\
\text { T5G2 } \\
\text { T6G2 }\end{array}$ & $\begin{array}{l}12 \\
12 \\
12 \\
12 \\
12 \\
12\end{array}$ & $5^{\text {a }}$ costela & $\begin{array}{l}\text { Clorhexidine } 2 \% \text {, } \\
\text { refrigerado a } 4^{\circ} \mathrm{C}\end{array}$ & $\begin{array}{c}30 \\
60 \\
90 \\
120 \\
150 \\
180\end{array}$ \\
\hline $\begin{array}{l}\text { T1G3 } \\
\text { T2G3 } \\
\text { T3G3 } \\
\text { T4G3 } \\
\text { T5G3 } \\
\text { T6G3 }\end{array}$ & $\begin{array}{l}12 \\
12 \\
12 \\
12 \\
12 \\
12\end{array}$ & $6^{\mathrm{a}}$ costela & $\begin{array}{l}\text { Criopreservação } \\
\text { em nitrogênio lí- } \\
\text { quido } a-196^{\circ} \mathrm{C}\end{array}$ & $\begin{array}{c}30 \\
60 \\
90 \\
120 \\
150 \\
180\end{array}$ \\
\hline $\begin{array}{l}\text { T1G4 } \\
\text { T2G4 } \\
\text { T3G4 } \\
\text { T4G4 } \\
\text { T5G4 } \\
\text { T6G4 }\end{array}$ & $\begin{array}{l}12 \\
12 \\
12 \\
12 \\
12 \\
12\end{array}$ & $7^{a}$ costela & $\begin{array}{l}\text { Solução de cloret } \\
\text { de sódio } 0,9 \% \text {, re- } \\
\text { frigerado a } 4^{\circ} \mathrm{C}\end{array}$ & $\begin{array}{c}30 \\
60 \\
90 \\
120 \\
150 \\
180\end{array}$ \\
\hline $\begin{array}{l}\text { T1G5 } \\
\text { T2G5 } \\
\text { T3G5 } \\
\text { T4G5 } \\
\text { T5G5 } \\
\text { T6G5 }\end{array}$ & $\begin{array}{l}12 \\
12 \\
12 \\
12 \\
12 \\
12\end{array}$ & $8^{a}$ costela & $\begin{array}{l}\text { Autoclavagem a } \\
132^{\circ} \mathrm{C} \text { por } 32 \text { minutos, } \\
\text { refrigerado a } 4^{\circ} \mathrm{C}\end{array}$ & $\begin{array}{c}30 \\
60 \\
90 \\
120 \\
150 \\
180\end{array}$ \\
\hline $\begin{array}{l}\text { T1G6 } \\
\text { T2G6 } \\
\text { T3G6 } \\
\text { T4G6 } \\
\text { T5G6 } \\
\text { T6G6 }\end{array}$ & $\begin{array}{l}12 \\
12 \\
12 \\
12 \\
12 \\
12\end{array}$ & $9^{a}$ costela & $\begin{array}{l}\text { Líquido de dakin } 0,5 \% \\
\text { refrigerado a } 4^{\circ} \mathrm{C}\end{array}$ & $\begin{array}{c}30 \\
60 \\
90 \\
120 \\
150 \\
180\end{array}$ \\
\hline $\begin{array}{l}\text { T1G7 } \\
\text { T2G7 } \\
\text { T3G7 } \\
\text { T4G7 } \\
\text { T5G7 } \\
\text { T6G7 }\end{array}$ & $\begin{array}{l}12 \\
12 \\
12 \\
12 \\
12 \\
12\end{array}$ & $10^{\mathrm{a}}$ costela & $\begin{array}{l}\text { Plasma homólogo, } \\
\text { congelado a }-12^{\circ} \mathrm{C}\end{array}$ & $\begin{array}{c}30 \\
60 \\
90 \\
120 \\
150 \\
180\end{array}$ \\
\hline $\begin{array}{l}\text { T1G8 } \\
\text { T2G8 } \\
\text { T3G8 } \\
\text { T4G8 } \\
\text { T5G8 } \\
\text { T6G8 }\end{array}$ & $\begin{array}{l}12 \\
12 \\
12 \\
12 \\
12 \\
12\end{array}$ & $11^{\mathrm{a}}$ costela & $\begin{array}{l}\text { Glicerina } 98 \%, \\
\text { refrigerado a } 4^{\circ} \mathrm{C}\end{array}$ & $\begin{array}{c}30 \\
60 \\
90 \\
120 \\
150 \\
180\end{array}$ \\
\hline
\end{tabular}

Quadro 2. Valores absolutos referentes à força máxima de resistência à micro-tração $(\mathrm{N})$ de ossos corticais de coelho preservados em diversos meios, por até 180 dias e a fresco

\begin{tabular}{ccccccccc}
\hline $\begin{array}{c}\text { Tempo } \\
\text { (dias)/meio } \\
\text { de pre- } \\
\text { servação }\end{array}$ & 1 & 2 & 3 & 4 & 5 & 6 & 7 & 8 \\
\hline $\begin{array}{c}\text { Osso a } \\
\text { fresco }\end{array}$ & 215,3 & 186,7 & 180 & 194,5 & 86,61 & 99,56 & 86,07 & 82,05 \\
30 & 163,3 & 125,8 & 143,2 & 111,7 & 77,92 & 98,79 & 81,77 & 20,17 \\
60 & 155 & 124,9 & 145,3 & 137,2 & 71,19 & 94,65 & 78,22 & 17,72 \\
90 & 137,3 & 111,4 & 133,3 & 110,2 & 63,58 & 94,04 & 77,05 & 10,6 \\
120 & 94,57 & 106 & 129,9 & 103,1 & 32,93 & 73,19 & 76,85 & 5,567 \\
150 & 71,92 & 97,97 & 126,6 & 100,1 & 13,9 & 79,09 & 74,66 & 2,13 \\
180 & 68,04 & 53,45 & 120,1 & 51,08 & 10,67 & 70,4 & 70,99 & 1,45 \\
& & & & & & & & \\
\hline
\end{tabular}

Quadro 3. Valores absolutos referentes à força de resistência à micro-tração, no momento da ruptura $(\mathrm{N})$, de ossos corticais de coelho preservados em diversos meios, por até 180 dias e a fresco

\begin{tabular}{ccccccccc}
\hline $\begin{array}{c}\text { Tempo } \\
\text { (dias)/meio } \\
\text { de pre- } \\
\text { servação }\end{array}$ & 1 & 2 & 3 & 4 & 5 & 6 & 7 & 8 \\
\hline $\begin{array}{c}\text { Osso a } \\
\text { fresco }\end{array}$ & 212,2 & 184,2 & 179,2 & 193 & 75,61 & 93,79 & 83,55 & 80,62 \\
30 & 144,3 & 124,6 & 141,6 & 145 & 74,08 & 92,64 & 75,71 & 18,44 \\
60 & 124,9 & 124,2 & 143,2 & 110,5 & 70,13 & 91,55 & 71,21 & 21,38 \\
90 & 147,9 & 101,7 & 131,8 & 107,2 & 60,1 & 89,96 & 64,8 & 11,16 \\
120 & 85,73 & 106,1 & 114,5 & 94,63 & 29,82 & 79,26 & 70,19 & 6,84 \\
150 & 70,26 & 93,64 & 102,7 & 92,13 & 13,72 & 69,31 & 66,57 & 3,27 \\
180 & 60,29 & 52,6 & 102,1 & 47,43 & 9,95 & 68,68 & 58,68 & 1,78
\end{tabular}

veis: força máxima atingida pela amostra e força atingida no momento da ruptura, ambas em Newton (N).

Análise dos resultados. Os valores absolutos obtidos para a força máxima de ruptura e para a força no momento da ruptura (Quadros 2 e 3) foram transformados em valores percentuais, considerando-se, para tanto, que 0 valor absoluto aferido nos ossos a fresco correspondeu a 100\% da resistência (Quadros 4 e 5), facilitando a observação da variação das forças testadas ao longo de todo o tempo de preservação, entre os diferentes pares de costela preservados. Os resultados foram submetidos à análise estatística com o uso do software Statistica 7.1 (Statsoft, INC. 2003), através da aplicação do teste de comparação entre duas proporções $(\mathrm{P}<0,05)$, considerando-se que as proporções apresentaram distribuição normal.

\section{RESULTADOS E DISCUSSÃO}

A determinação da força de resistência de fragmentos ósseos, preservados para transplante, se torna importante a partir do momento no qual o enxerto, quando aplicado cirurgicamente, será submetido à aplicação de diversas forças, como tração, rotação, compressão e cisalhamento (Keating \& McQueen 2001). A atuação destas forças, sobre um enxerto com pouca capacidade de resistência, pode originar fraturas e perda da função do membro, comprometendo a reabilitação do paciente ao exercício de sua função locomotora (Fitch et al. 1997). Portanto, os ensaios biomecânicos são importantes testes 
de triagem nas pesquisas que envolvem modelos experimentais aplicados em cirurgias ortopédicas, como já descrito por Duarte \& Schaeffer (2000) e Giovani et al. (2006).

A revisão da literatura apresenta muitos artigos fundamentados na investigação da viabilidade de utilização de diferentes técnicas de preservação de ossos corticais para enxertos heterólogos; porém, a análise destes trabalhos científicos revela diferenças metodológicas, o que inclui os modelos animais de experimentação e os métodos utilizados na análise dos materiais, com poucas referências aos testes físicos de resistência das amostras ao final do período de preservação (Del Carlo et al. 1999, Cavassini et al. 2001, Matter et al. 2001). O presente artigo consistiu na investigação de diversas técnicas de preservação de ossos corticais, padronizando-se o modelo animal e o método de avaliação da resistência ao teste de microtração, o que permitiu uma comparação igualitária entre as técnicas de preservação investigadas.

Os Quadros 2 e 3 apresentam, respectivamente, os valores absolutos da força máxima e da força no momento da ruptura, ambas mensuradas em Newton, durante a realização do teste de resistência à micro-tração. Os valores das tabelas acima mencionadas estão representados graficamente pelas Figuras 1 e 2, e demonstram que, ao final do experimento, houve redução da resistência de todos os ossos submetidos ao teste de micro-tração, in-

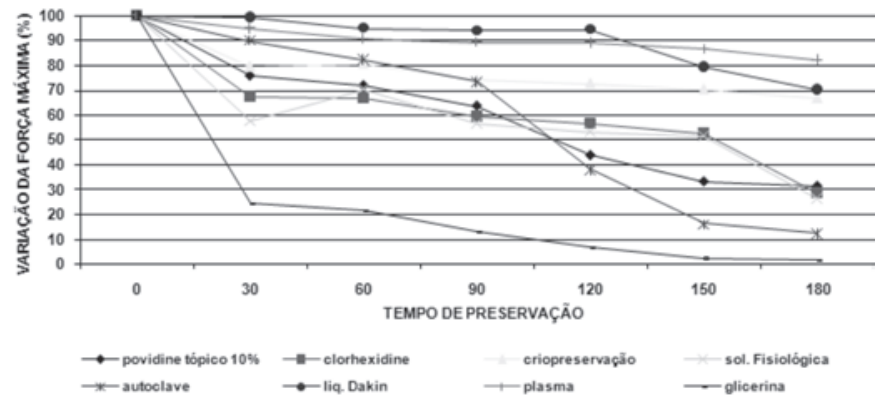

Fig.1. Representação gráfica da variação da força máxima de resistência à micro-tração $(\mathrm{N})$ de fragmentos de costela de coelhos preservados em diversos meios por até 180 dias e a fresco (tempo 0).

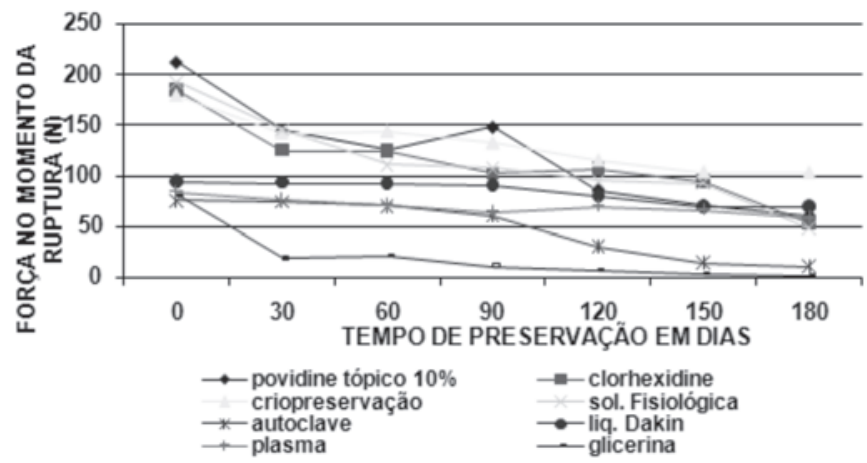

Fig.2. Representação gráfica da variação da força de resistência à micro-tração $(\mathrm{N})$, no momento da ruptura, de fragmentos de costela de coelhos preservados em diversos meios por até 180 dias e a fresco (tempo 0). dependente do meio de preservação. A glicerina foi o meio com menor capacidade de preservação da força presente no osso a fresco $(82,05 \mathrm{~N})$, demonstrando uma curva acentuada de queda da resistência já aos 30 dias, quando a força máxima atingiu $20,17 \mathrm{~N}$, mantendo a mesma tendência até o fim do experimento, momento em que a força máxima mensurada foi de apenas 1,45N (Fig.1 e 2). A pouca capacidade de preservação da resistência de amostras preservadas em glicerina já havia sido identificada por Costa (1996), o qual concluiu que a utilização da glicerina interfere diretamente na capacidade de sustentação biomecânica dos enxertos utilizados em grandes falhas ósseas, apesar de a mesma não interferir nas funções osteoindutora e osteocondutora dos ossos transplantados. A pouca resistência física dos ossos preservados em glicerina também foi observada por Del Carlo et al. (1999), durante pesquisa de 6 diferentes meios de conservação de aloenxertos ósseos, demonstrando que a glicerina $98 \%$ alterou as propriedades biomecânicas das amostras, além de não ter preservado a esterilidade das mesmas.

Apesar dos resultados terem demonstrado progressiva diminuição da resistência dos ossos preservados na glicerina, outros estudos atestam que este meio preserva as características osteoindutora dos fragmentos ósseos, como demonstrado por Cavassini et al. (2001), os quais, através da análise histopatológica, notaram atividade osteogênica 30 dias após a aplicação de enxertos mantidos em glicerina a $98 \%$ por um período de 30 dias.

As amostras submetidas à autoclavagem e aquelas preservadas na solução de povidine passaram a apresentar maior intensidade na diminuição da resistência a partir dos 90 dias de preservação. Os demais meios, representados pelas amostras criopreservadas em nitrogênio líquido e aquelas mantidas no plasma homólogo e no líquido de dakin, demonstraram maior estabilidade quanto às características biomecânicas, apresentando curvas com menores inclinações ao longo de todo o período de observação (Fig.1 e 2).

Os Quadros 4 e 5 foram organizados utilizando-se os valores absolutos apresentados pelos Quadros 2 e 3. Como cada grupo utilizou amostras referentes a um único par de costelas, para se efetuar a comparação entre os vários métodos de preservação, procedeu-se ao cálculo da percentagem de variação da força de resistência com relação à força presente no osso a fresco (T0), e em cada período de tempo de preservação. Para tanto, utilizou-se regra de 3 simples, considerando-se o valor absoluto da força máxima ( $\mathrm{N}$ ) e da força no momento da ruptura $(\mathrm{N})$, aferidas no osso a fresco, como correspondendo a $100 \%$, e comparando com o valor absoluto aferido em cada intervalo de observação. Desta forma, obteve-se o percentual de manutenção da força máxima e da força no momento da ruptura em relação ao osso fresco, em todos os intervalos, permitindo uma comparação equivalente entre os diferentes pares de costela mantidos nos meios de preservação pesquisados. Estes dados, representa- 
Quadro 4. Variação da força máxima de resistência à micro-tração, em percentagem, de fragmentos de ossos de coelho preservados em diversos meios por até 180 dias, comparada com a força do osso a fresco. Os valores foram obtidos utilizando-se os dados do Quadro 2, mediante a aplicação de regra de 3 simples, considerando-se, para tanto, o valor do osso fresco como $100 \%$

\begin{tabular}{|c|c|c|c|c|c|c|c|c|}
\hline $\begin{array}{c}\text { Tempo (dias)/ } \\
\text { meio de } \\
\text { preservação }\end{array}$ & 1 & 2 & 3 & 4 & 5 & 6 & 7 & 8 \\
\hline Osso a fresco & $A^{*} 100 a^{* *}$ & A100a & A100a & $\mathrm{A} 100 \mathrm{a}$ & A100a & A100a & $\mathrm{A} 100 \mathrm{a}$ & A100a \\
\hline 30 & B75,84bcd & $\mathrm{B} 67,38 \mathrm{bc}$ & AB79,55cde & BC57,42ab & A89,96cde & A99,22e & A95,00de & $\mathrm{B} 24,58 \mathrm{a}$ \\
\hline 60 & $\mathrm{~B} 71,99 \mathrm{bc}$ & $\mathrm{B} 66,89 \mathrm{~b}$ & $\mathrm{AB} 80,72 \mathrm{bc}$ & $\mathrm{B} 70,53 \mathrm{bc}$ & $\mathrm{A} 82,19 \mathrm{bc}$ & AB95,06c & A90,87bc & B21,59a \\
\hline 90 & $\mathrm{BC} 63,77 \mathrm{bc}$ & BC59,66bc & $\mathrm{B} 74,05 \mathrm{bcd}$ & $\mathrm{BC} 56,65 \mathrm{~b}$ & $\mathrm{~B} 73,40 \mathrm{bcd}$ & AB94,04d & A89,52cd & $\mathrm{B} 12,91 \mathrm{a}$ \\
\hline 120 & $\mathrm{BC} 43,92 \mathrm{bc}$ & BC $56,77 \mathrm{bc}$ & $\mathrm{B} 72,66 \mathrm{~cd}$ & $\mathrm{BC} 53,00 \mathrm{bc}$ & $\mathrm{C} 38,02 \mathrm{~b}$ & AB94,45d & $A 89,28 d$ & $\mathrm{~B} 6,78 \mathrm{a}$ \\
\hline 150 & $\mathrm{C} 33,40 \mathrm{bc}$ & BC52,47cd & B70,33de & BC51,46cd & $\mathrm{C} 16,04 \mathrm{ab}$ & AB79,43de & A86,74de & $B 2,59 a$ \\
\hline 180 & $\mathrm{C} 31,60 \mathrm{~b}$ & $\mathrm{C} 28,62 \mathrm{~b}$ & $\mathrm{~B} 66,72 \mathrm{c}$ & $\mathrm{C} 26,26 \mathrm{ab}$ & $\mathrm{C} 12,31 \mathrm{ab}$ & $\mathrm{B} 70,34 \mathrm{C}$ & $\mathrm{A} 82,47 \mathrm{C}$ & $\mathrm{B} 1,76 \mathrm{a}$ \\
\hline
\end{tabular}

* Letras maiúsculas iguais na mesma coluna significam que não houve diferença estatística entre os intervalos de observação para as amostras do mesmo grupo, no teste de comparação entre duas proporções $(P<0,05)$.

** Letras minúsculas iguais na mesma linha significam que não houve diferença estatística entre os meios de preservação no mesmo momento de observação, no teste de comparação entre duas proporções $(P<0,05)$.

Quadro 5. Variação da força de resistência à micro-tração no momento da ruptura, em percentagem, de fragmentos de ossos de coelho preservados em diversos meios por até 180 dias, comparada com a força do osso a fresco. Os valores foram obtidos utilizando-se os dados do Quadro 3, mediante a aplicação de regra de 3 simples, considerando-se, para tanto, o valor do osso a fresco como $100 \%$

\begin{tabular}{|c|c|c|c|c|c|c|c|c|}
\hline $\begin{array}{c}\text { Tempo (dias)/ } \\
\text { meio de } \\
\text { preservação }\end{array}$ & 1 & 2 & 3 & 4 & 5 & 6 & 7 & 8 \\
\hline Osso a fresco & $A^{*} 100 a^{* *}$ & A100a & A100a & A100a & A100a & A100a & A100a & A100a \\
\hline 30 & $\mathrm{~B} 68,00 \mathrm{bcd}$ & $\mathrm{B} 67,64 \mathrm{bc}$ & A79,10cde & B75,12ab & A97,97cde & A98,77e & AB90,61de & $B 22,87 a$ \\
\hline 60 & BC58,86bc & B67 & $1 \mathrm{bc}$ & BC57,25bc & A92,75bc & $1 c$ & $A B 85,23 b c$ & B26,51a \\
\hline 90 & $\mathrm{~B} 69,70 \mathrm{bc}$ & BC55,21bc & $\mathrm{B} 73,55 \mathrm{bcd}$ & BC55,54b & A79,48bcd & A95,91d & $\mathrm{B} 77,55 \mathrm{~cd}$ & $\mathrm{~B} 13,84 \mathrm{a}$ \\
\hline 120 & $\mathrm{BC} 40,38 \mathrm{bc}$ & BC57,60bc & $\mathrm{B} 63,89 \mathrm{~cd}$ & BC $49,03 b c$ & $\mathrm{~B} 39,43 \mathrm{~b}$ & $A 84,50 d$ & $\mathrm{AB} 84,00 \mathrm{~d}$ & $\mathrm{~B} 8,48 \mathrm{a}$ \\
\hline 150 & $\mathrm{C} 33,11 \mathrm{bc}$ & BC50,83cd & B57,31de & $\mathrm{BC} 47,73 \mathrm{~cd}$ & $\mathrm{~B} 18,14 \mathrm{ab}$ & $\mathrm{B} 73,22 \mathrm{de}$ & AB79,67de & $\mathrm{B} 40,60 \mathrm{a}$ \\
\hline 180 & $\mathrm{C} 28,41 \mathrm{~b}$ & C28,55b & B56,97c & C24,57ab & B13,15ab & $\mathrm{B} 73,90 \mathrm{c}$ & B70,23c & B2,20a \\
\hline
\end{tabular}

* Letras maiúsculas iguais na mesma coluna significam que não houve diferença estatística entre os intervalos de observação para as amostras do mesmo grupo, no teste de comparação entre duas proporções $(P<0,05)$.

** Letras minúsculas iguais na mesma linha significam que não houve diferença estatística entre os meios de preservação no mesmo momento de observação, no teste de comparação entre duas proporções $(P<0,05)$.

dos graficamente pelas Figuras 3 e 4, demonstraram que o Grupo 7, cujos ossos permaneceram congelados em plasma homólogo, apresentou, proporcionalmente, maior resistência ao final do experimento, com a manutenção, em média, de $82,47 \%$ da força máxima de resistência à micro-tração e $70,23 \%$ da força no momento da ruptura. Em seguida encontrou-se o Grupo 6, cujos ossos foram preservados sob refrigeração no líquido de Dakin, com a manutenção de $70,71 \%$ da força máxima e $73,9 \%$ da força no momento da ruptura, seguido dos ossos criopreservados, os quais mantiveram, em média, ao final do experimento, $66,72 \%$ da força máxima e $56,97 \%$ da força no momento da ruptura. Nesta comparação, os ossos preservados em glicerina mais uma vez obtiveram o menor índice, apresentando, ao final do experimento, apenas $1,76 \%$ da força máxima e $2,2 \%$ da força no momento da ruptura, utilizando como referência a força presente no osso a fresco. A autoclavagem também apresentou índices baixos ao final do experimento, mantendo apenas $12,31 \%$ da força máxima e $13,15 \%$ da força no momento da ruptura aos 180 dias. Já os ossos preservados nas soluções de povidine e clorhexidine, além daqueles mantidos refrigerados em solução fisiológica, demonstraram resultados intermediários, quando comparados com os demais grupos. Ambos mantiveram, ao final do experimento, respectivamente, $31,6 \% ; 28,62 \%$ e $26,26 \%$ da for-

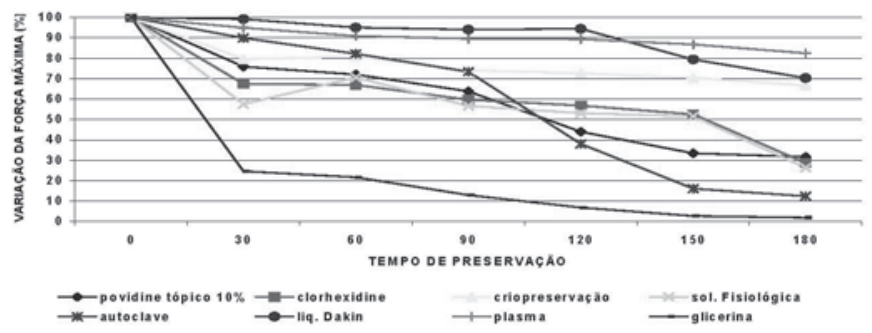

Fig.3. Representação gráfica da variação da força máxima de resistência à micro-tração de fragmentos de ossos de coeIho preservados em diversos meios por até 180 dias, comparada com a força do osso a fresco, em percentagem. Os valores foram obtidos mediante a aplicação de regra de 3 simples, considerando-se, para tanto, o valor do osso a fresco como $100 \%$. 


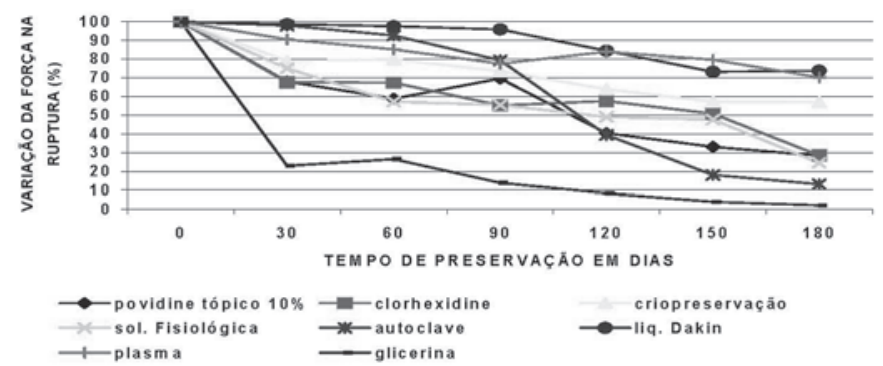

Fig.4. Representação gráfica da variação da força de resistência à micro-tração no momento da ruptura de fragmentos de ossos de coelho preservados em diversos meios por até 180 dias, comparada com a força do osso a fresco, em percentagem. Os valores foram obtidos mediante a aplicação de regra de 3 simples, considerando-se, para tanto, o valor do osso a fresco como $100 \%$.

ça máxima presente no osso a fresco, demonstrando uma diferença inferior a $5 \%$ entre os grupos (Fig.3 e 4).

Diante dos resultados acima descritos, observou-se que o congelamento apresentou boa capacidade de manutenção das propriedades biomecânicas entre os meios testados; porém, como também demonstrado por Matter et al. (2001), esta técnica não impede que ocorra diminuição da resistência durante o período de observação. Já, nos estudos efetuados por Duarte \& Schaeffer (2000), os autores concluíram que o congelamento do osso no seu estado natural, a $-80^{\circ} \mathrm{C}$, e a liofilização seguida do congelamento, a $-40^{\circ} \mathrm{C}$, não apresentaram diferenças significativas ao teste de compressão após 30 dias de preservação. Complementando estas informações sobre as características biomecânicas dos enxertos congelados e liofilizados, Galia et al. (2005), afirmaram que o congelamento seguido da liofilização também contribuiu para a diminuição da antigenicidade, reduzindo o risco de rejeição, mesmo com a utilização de implantes ósseos heterólogos. Porém, Baptista et al. (2003) afirmaram que, apesar de o congelamento seguido da liofilização ter contribuído para a diminuição da antigenicidade dos enxertos, esta técnica de preparo reduziu substancialmente a resistência do implante.

Os Grupos 1, 2 e 4 apresentaram resultados intermediários com relação à manutenção da resistência ao final do experimento, o que pode ser atestado pelas curvas dos gráficos ilustrados pelas Figuras 1 a 4, onde se observa que ambos mantiveram resistência superior a $50 \%$ daquela verificada no osso a fresco após 30 dias de preservação, mantendo valores aproximados a este até os 120 dias, quando passaram a apresentar diminuição mais acentuada da força máxima de resistência e da força de resistência no momento da ruptura. Os 3 meios de preservação com melhores resultados, representados em ordem decrescente pelos Grupos 7, 6 e 3, apresentaram, em todos os gráficos, curvas menos acentuadas de declínio, demonstrando maior estabilidade biomecânica quando em contato com os meios nos quais permaneceram preservados, o que se comprovou pela análise estatística, a qual não identificou diminuição significativa da resistência entre os intervalos observados, quando comparados com os demais meios testados. Estas observações vão de encontro às pesquisas realizadas por Del Carlo et al. (1999), os quais verificaram, pela análise de diferentes meios de preservação, que existe alteração das características físicas de amostras de osso cortical durante o tempo de conservação, e que os métodos utilizados interferem nas características físicas das amostras.

Apesar de alguns meios terem mantido as características físicas macroscópicas aparentemente inalteradas, a análise estatística do teste biomecânico aplicado demonstrou que a resistência apresentou importantes alterações durante o período de preservação, como verificado pelos resultados aqui apresentados e pelas observações realizadas por outros autores (Cavassini et al. 2001, Matter et al. 2001, Amendola et al. 2003).

Contudo, as variações na capacidade de resistência dos ossos durante o tempo de preservação não eliminam a possibilidade de utilização dos meios nos bancos de ossos, visto que além das características biomecânicas, devese também considerar os efeitos osteoindutor e osteocondutor das amostras; bem como as características imunológicas, importantes na decisão sobre os métodos de preservação, visto que, à medida que ocorre diminuição da antigenicidade dos enxertos, aumenta-se a possibilidade de incorporação dos mesmos e reduz-se o período de risco para a perda do osso transplantado (Boyce et al. 1999, Lewandrwski et al. 2001, Baptista et al. 2003).

\section{CONCLUSÕES}

Os resultados anteriormente apresentados permitiram concluir que o método e o tempo de preservação interferiram diretamente nas características biomecânicas dos ossos corticais, promovendo a diminuição progressiva da capacidade de resistência à micro-tração ao longo do período de preservação.

Dos meios testados, a glicerina apresentou menor capacidade de preservação da força física em todos os momentos de observação; enquanto que as amostras mantidas no plasma homólogo congelado apresentaram melhores resultados na capacidade de preservação da força de resistência ao teste de micro-tração.

Os ossos criopreservados e aqueles mantidos refrigerados na solução de Dakin também apresentaram resultados satisfatórios, compatíveis com a indicação para a utilização em bancos de ossos corticais, visto que apresentaram baixo custo operacional e facilidade na execução da técnica de preparo e preservação.

\section{REFERÊNCIAS}

Amendola G.F., Ilha M., Berger R., Stedile R. \& Schossler J.E. 2003. Correção de defeito ósseo femural em cães utilizando implante cortical homólogo conservado em mel. Acta Cirúr. Bras. 18:302-307.

Baptista A.D., Sorrilha A., Tormes T.A.M., Abdoune Y.A., Croci A.T., Camargo O.P. \& Oliveira C.R.G.C.M. 2003. Estudo histológico dos enxertos ósseos homólogos humanos. Acta. Ortop. Bras. 11(4):220224.

Barros S.V.S.G., Del Carlo R.J., Viloria M.IV., Galvão S.R. \& Filho A.M. 
2001a. Auto-enxerto percutâneo de medula óssea em coelhos. I. Coleta, preparo e aplicação. Ciência Rural 31:1013-1018.

Barros S.V.S.G., Del Carlo R.J., Viloria M.I.V., Galvão S.R., Filho A.M. \& Oliveira D.R. 2001b. Auto-enxerto percutâneo de medula óssea ii. Reparação de falhas segmentares produzidas no rádio de coelhos. Ciência Rural 31:627-632.

Boyce T., Edwards J. \& Scarborough N. 1999. Allograft bone. The influence of processing on safety and performance. Orthop. Clin. North Am. 30:571-581.

Cavassani M.M., Moraes J.R.E. \& Filho J.G.P. 2001. Função osteoindutora de fragmentos ósseos conservados em glicerina a $98 \%$ : estudo experimental em ratos. Ciência Rural 31:445-448.

Costa J.L. 1996. Reconstrução de grande falha óssea com enxerto cortical alógeno conservado em glicerina, fixado com placas e parafuso de aço inoxidável da série 304: estudo experimental em cães. Dissertação de Mestrado, Universidade Estadual Paulista, Jaboticabal.

Cunha F.M., Braga G.F., Drumond Júnior S.N. \& Figueiredo C.T. 1998. Epidemiologia de 1.212 fraturas expostas. Revta Bras. Ortop. 33 (6): 451-6.

Del Carlo R.J., Galvão S.R., Viloria M.I.V. \& Souza T.D. 1999. Aloenxertos ósseos caninos diferentemente preservados. Rev. Bras. Cirur. Vet. 6:11-16.

Del Carlo R.J., Kawata D., Viloria M.I.V., Oliveira D.R., Silva A.S., Marchesi D.R., Galvão S.R., Azevedo P. \& Monteiro B.S. 2003a. Polímero derivado de mamona acrescido de cálcio, associado ou não à medula óssea autógena na reparação de falhas ósseas. Ciência Rural 33:1081-1088.

Del Carlo R.J., Silva A.M., Viloria M.I.V., Fonseca C.C. \& Oliveira D.R. 2003b. Potencial osteoindutor da matriz óssea homóloga desmineralizada de coelho. Ciência Rural 33:533-538.

Duarte L.S. \& Schaeffer L. 2000. Comparação da resistência à compressão de ossos bovinos congelados e liofilizados. Revta Bras. Eng. Biomédica 16:89-93.

Feofiloff E.T. \& Jesus-Garcia R. 1996. Técnicas de obtenção, processamento, armazenamento e utilização de homoenxertos ósseos. Protocolo do banco de ossos da Escola Paulista de Medicina. Revta Bras. Ortop. 31 (11): 895-903.

Fitch R., Kerwin S., Newman-Gage H. \& Sinibaldi K.R. 1997. Bone autografts and allografts in dogs. Comp. Cont. Educ. Small Anim. Pract. 19:558-578.

Franco K.L., Borges A.P.B., Viloria M.I.V., Fernandes E.S. \& Fehlberg A.F. 2001. Hidroxiapatita sintética pura, hidroxiapatita sintética associada ao colágeno e hidroxiapatita sintética associada ao lipossomo como substitutos ósseos em efeitos provocados na tíbia de cães: aspectos da osteointegração à microscopia de luz transmitida. Arq. Bras. Med. Vet. Zootec. 53:431-436.

Galia C.R., Rosito R., Mello T.M. \& Macedo C. 2005. Uso de enxerto ósseo homólogo e heterólogo em diáfise femoral de ratos: comparação entre enxerto ósseo congelado e liofilizado. Revta Bras. Ortop. 40(3):141-146.

Giordano V., Albuquerque R.P., Resende R., Senna L.F., Pompei A., Amaral N.P., Giordano M., Apfel M.I.R. \& Bastos J.S. 2006. Estudo histomorfológico da incorporação de aloenxerto fresco e da hidroxiapatita de alta porosidade em defeito ósseo produzido em fêmures de ratos. Revta Bras. Ortop. 41(9):384-391.
Giovani A.M.M., Croci A.T., Oliveira C.R.G., Filippi R.Z., Santos L.A.U., Maragni G.G. \& Albhy T.M. 2006. Comparative study of cryopreserved bone tissue and tissue preserved in a $98 \%$ glycerol solution. Clinics 16:565-570.

Keating J.F. \& McQueen M.M. 2001. Substitutes for autologous bone graft in orthopaedic trauma. J. Bone Joint Surg. 83:3-8.

Lewandrwski K.U., Rebman V. \& Passler M. 2001. Immune response to perforated and partially demineralized bone allografts. J. Orthop. Sci. 6: 545-55.

Lourenço P.R.B. \& Franco J.S. 1998. Atualização no tratamento das fraturas expostas. Rev. Bras. Ortop. 33(6):436-446.

Macedo C.A.S., Galia C.R., Silva A.L.B., César P.C., Sanches P.R.S., Duarte L.S. \& Müller L.M. 1999. Comparação da resistência à compressão do osso bovino congelado e liofilizado. Revta Bras. Ortop. 34 (9/10): 529-534.

Matter H.P., Garrel T.V., Bilderbeek U., Mittelmeier W. 2001. Biomechanical examinations of cancellous bone concerning the influence of duration and temperature of cryopreservation. J. Biomed. Mater. Res. 55:40-44.

Miranda E.S., Cardoso F.T.S., Medeiros Filho J.F., Barreto M.D.R., Teixeira R.M.M., Wanderley A.L. \& Fernandes K.E. 2005. Estudo experimental comparativo no uso de enxerto ósseo orgânico e inorgânico no reparo de fraturas cirúrgicas em rádio de coelhos. Acta Ortop. Bras. 13(5):245-248.

Saraiva G.L. \& Lazaretti-Castro M. 2002. Marcadores bioquímicos da remodelação óssea na prática clínica. Arq. Bras. Endocrinol. Metabol. 46:72-78.

Silva A.B.D., Rodrigues L., Jorgetti W., Besteiro J.M., Ferreira M.C., Gonçalves C.G. \& Reis L.M. 2000a. Alterações histológicas em enxerto de osso homógeno preparado e armazenado com duas técnicas diferentes. Acta Cirúr. Bras. 15:74-77.

Silva A.B.D., Rodrigues, L., Jorgetti W., Besteiro J.M., Ferreira M.C., Gonçalves C.G., Reis L.M. \& Groth A.K. 2000b. Retalho ósseo préfabricado com osso homógeno: estudo da maturação óssea em um modelo experimental. Acta Cirúr. Bras. 15:65-68.

Silva A.M., Del Carlo R.J., Viloria M.I.V., Silva A.S. \& Filgueiras R.R. 2003. Matriz óssea homóloga desmineralizada na preparação de faIhas ósseas segmentares produzidas no rádio de coelhos. Ciência Rural 33:539-345.

Statsoft Inc. 2003. Livro Base: data analysis software system, version 7.1. São Caetano do Sul: copyright Statsoft. 142p.

Sun J.S., Lin F.H., Wang Y.J., Huang Y.C., Chueh S.C., Hsu F.Y. 2003. Collagen-hydroxyapatite/tricalcium phosphate microspheres as a delivery system for recombinant human transforming growth factor(beta)1. Artificial Organs 27:605-612.

Vieira J.G.H. 1998. O papel dos marcadores bioquímicos do metabolismo ósseo no diagnóstico e seguimento laboratorial das doenças osteometabólicas. Revta Bras. Clín. Terap. 24:73-76.

Volpon J.B. \& Costa R.M.P. Ensaio mecânico e uso clínico do enxerto ósseo processado. 2000. Revta Bras. Ortop. 35(6):219-224.

Zambuzzi W.F., Oliveira R.C., Piozzi R., Cestari T.M., Taga R., Buzalaf M.A.R. \& Granjeiro J.M. 2006. Avaliação histológica do implante do osso fetal bovino acelular e desmineralizado em subcutâneo de ratos. Revta Bras. Ortop. 41(6):227-232. 